\title{
Simultaneous growth of several bicrystals oriented by common single-crystal seed
}

\author{
Yu.G.Kazarov \\ B.Verkin Institute for Low Temperature Physics and Engineering, \\ National Academy of Sciences of Ukraine, 47 Lenin Ave., 61103 Kharkiv, \\ Ukraine
}

Received March 24, 2015

\begin{abstract}
The hetero-homoepitaxy phenomenon is shown efficient for simultaneous growth of five Zn-bicrystals identically oriented by one single-crystal seed. The crystallographic, geometrical and thermal requisites to achieve the successful growth and specify the grain boundary orientation identical for all bicrystals are analyzed for closely packed pure metals.
\end{abstract}

Keywords: growth models, bridgman technique, growth from melt, selective epitaxy, zinc

Показана возможность эффективного использования явления гетеро-гомоэпитаксии для одновременного выращивания серии идентичных бикристаллов, ориентированных общей монокристаллической затравкой. Проанализированы геометрические и теплофизические условия успешного роста бикристаллов чистых ГПУ-металлов с заранее заданной ориентацией границы зерен.

Одночасне вирощування кількох бікристалів, орієнтованих загальною затравкою. Ю.Г.Казаров

Показано можливість ефективного використання явища гетеро-гомоепітаксії для одночасного вирощування декількох ідентичних бікристалів, орієнтованих однією монокристалічною затравкою. Проаналізовано геометричні та теплофізичні умови успішного росту бікристалів чистих ГЩУ-металів з наперед заданою орієнтацією межі зерен.

\section{Introduction}

Metals and alloys as engineering materials are used predominantly in polycrystalline state which means that their strength, ductility and other physical properties are dependent on the grain size and grain boundaries (GB) nature. Hence, the effect of grain boundaries on the properties of the polycrystalline materials is one of the topical problems of physics. Its solution determines to a large extent of development of the new technologies to create materials with the given properties. The basic approaches to this problem, the main methods, obtained results and actual difficulties in understanding the role of the GB are discussed in [1-3] and other studies.

In this way it is appropriate to begin studies using simple object, for example, bicrystal with only one boundary between two grains. During growth the misorientation of grains in the bicrystal is determined as a rule by two single-crystal seeds [2, 4]. However, in this case the configuration and orientation of the formed GB are arbitrary, representing a considerable challenge for the further investigations. Special growth mold with two projections reserved along the opposite walls was proposed in [4] as a way to keep the GB at the given position. Two grooves in the bicrystal corresponding to these projections serve as obstacles re- 


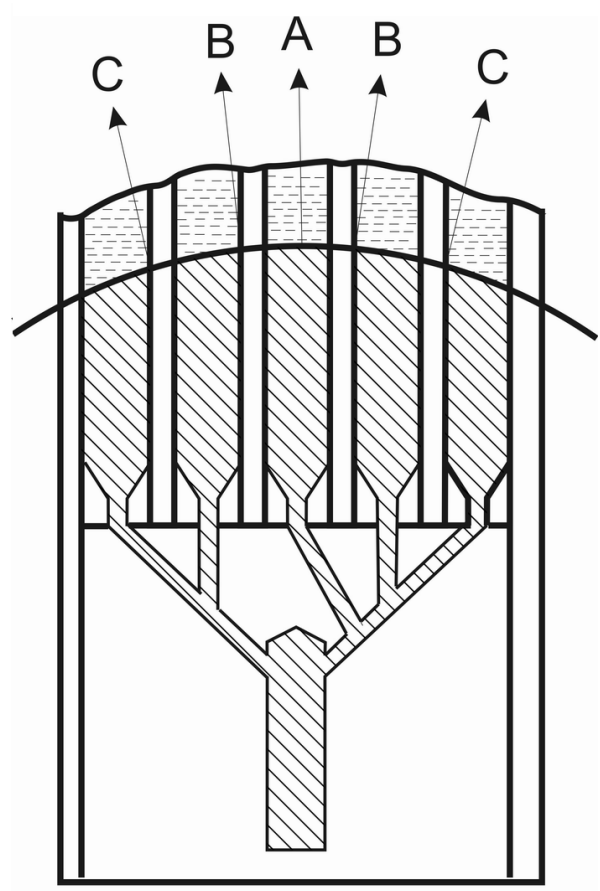

Fig. 1. Scheme of the mold unit for simultaneous growth of five bicrystals oriented by one single-crystal seed. Vectors A, B, C are normals to the crystallization front.

quiring the additional overcome energy for the GB. Unfortunately, this method to keep the given orientation of the GB is related to the high internal stresses generated in the bicrystal.

Another approach to the growing of the oriented bicrystal was developed at B.I.Verkin Institute for Low Temperature Physics and Engineering [5]. The method is based on so-called phenomenon of hetero-homoepitaxy (HHE). The HHE was revealed throughout our experiments of oriented single-crystals growth when some parasitic crystals of regular orientation were observed and investigated [6]. These parasitic crystals (if observed) had a regular and simultaneous orientation relative to the mold surface at the nucleation point (heteroepitaxy) and to the native crystal growing from the seed (homoepitaxy). These features of the parasitic crystals explaining the title of the phenomenon were applied for growth of the oriented bicrystal, in particular, for the so-called special boundary forming at the special misorientation angles between two grains [6]. Plot of the surface energy of the special boundary on the misorientation angle is characterized by a deep minimum. As a result at the given misorientation the formed plane special boundary occupies the special crystallographic position in the coin-

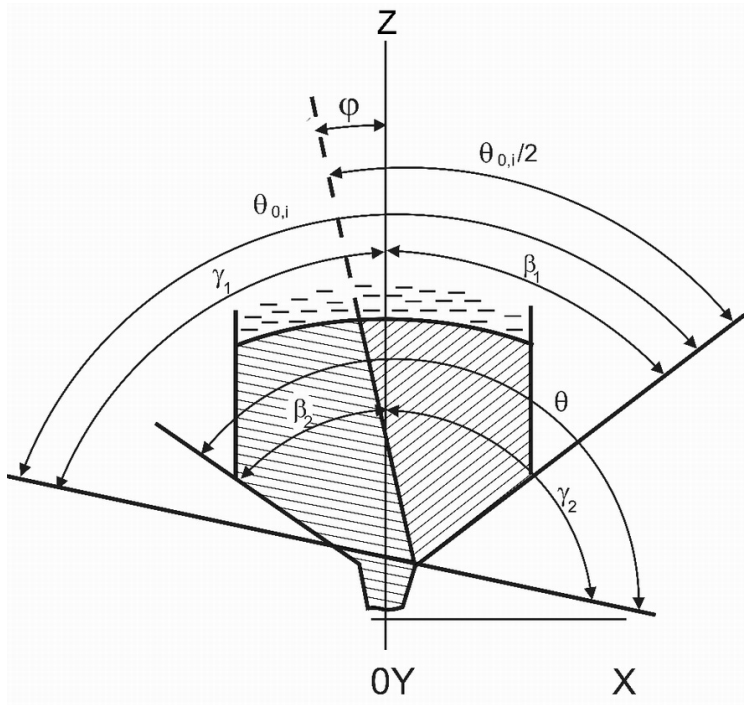

Fig. 2. Scheme of bicrystal growth (see the text). Orientations of the planes (0001) in two grains are indicated by shading angels.

cidence sites lattice (CSL). On the grounds of the HHE approach it was described simultaneous growth of several single-crystals equally oriented by the same singlecrystal seed [7]. This method was applied in [6] to growth of the singular bicrystal of $\mathrm{Zn}$ or Cd with the main grain oriented by the single-crystal seed and the other grain nucleated due to $\mathrm{HHE}$ in the inclined wall of the mold. In that way the growth of singular bicrystal oriented by only one singlecrystal seed was found feasible. Taking into account the obtained results it is not ruled out to achieve the simultaneous growth of several bicrystals oriented by a common single-crystal seed, as in the case of the singlecrystal growth.

The goal of this study is to give evidence of simultaneous growth of several bicrystals oriented by a common single-crystal seed exploiting the hetero-homoepitaxy phenomenon.

\section{Experimental}

The special growth mold shown in Fig. 1 was designed and manufactured for five bicrystals. Unlike the standards, special tilt angles of the mold planes were archived in the seed-crystal area. The values of the tilt angles were calculated according to the terms required for $\mathrm{HHE}$. The mean term of the HHE may be expressed by the following geometric formula [6]

$$
\theta_{0, i} \pm \Delta \theta_{0, i}=\beta+\gamma
$$




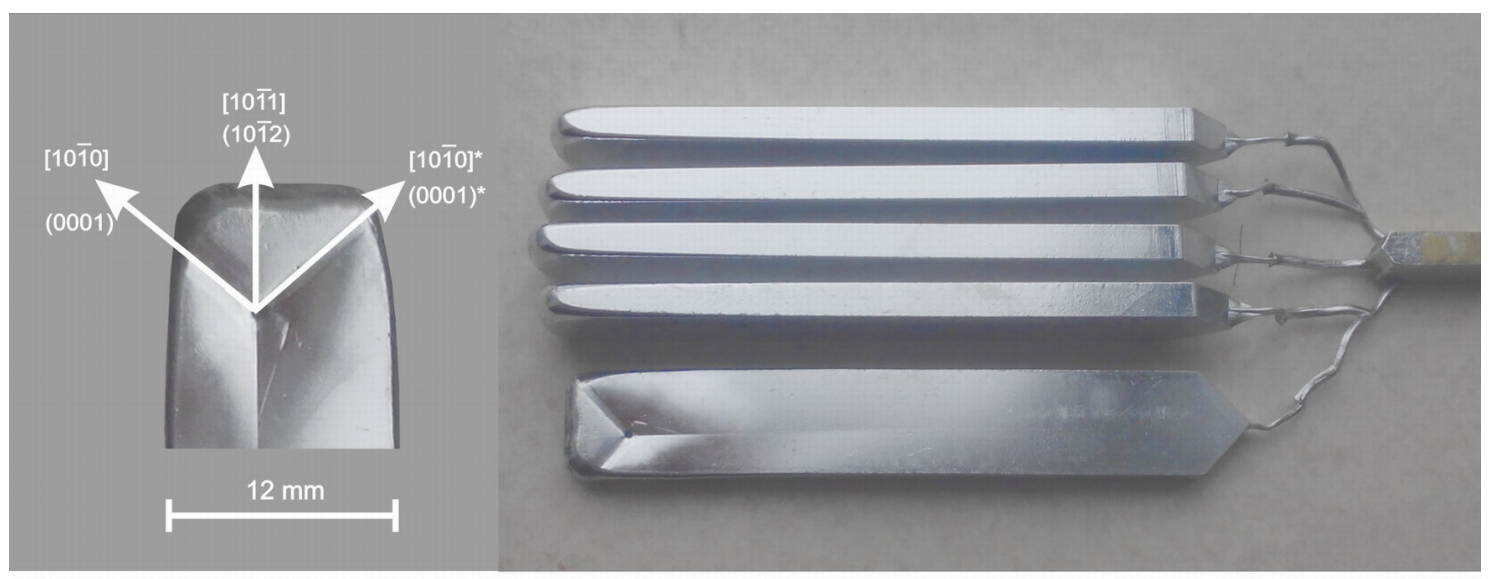

Fig. 3. Five Zn bicrystals (photo) grown simultaneously from one single-crystal seed. The bicrystal turned by $90^{\circ}$ was indented to visualize the longitudinal grain boundary trace and two traces corresponding to (0001) planes of each grain.

were $\theta_{0, i}$ is special misorientation angle (see Fig. 2), $\Delta \theta_{0, i}$ is half-width of the trough base in the boundary energy vs. misorientation angle curve (range where the special misorientation behaviors are valid), $\beta$ is tilt angle between plane and axis of the mold, $\gamma$ is angle between the closest packet plane of the seed lattice (i.e. the plane (0001)) and the longitudinal axis.

The following geometric conditions must be specified to provide the oriented bicrystal growth: rotation axis $\langle u v t w\rangle$, special misorientation angle, $\theta_{0, i}$, the grain boundary orientation, i.e. angle $\varphi$ between the boundary plane and the longitudinal axis of the mold. To ensure these conditions the tilt angle of one of the planes (see Fig. 2) must obey the equality [5]

$$
\beta_{1}=\theta_{0, i}-\gamma_{1} \text {. }
$$

Equation (2) describes a favorable condition for nucleation and growth of the HHEnucleus on $\beta_{1}$-tilt plane. The other tilt plane angel must satisfy to the equality

$$
\beta_{2}=\theta-\left(180^{\circ}-\gamma_{2}\right),
$$

where $\theta$ is nonspecial misorientation angle ranged between two neighbors special misorientation angels

$$
\theta_{0, i}+\Delta \theta_{0, i}<\theta<\theta_{0,(i+1)}-\Delta \theta_{0,(i+1)}
$$

Fulfilled the expressions (3) and (4), the growth of a nucleus if it appears on $\beta_{2}$-tilt plane becomes inhibited. This provides favorable conditions of the growth for the main grain nucleated on the seed. As a re- sult of the joint growth of the main grain and the HHE-grain a bicrystal becomes formed. Moreover, the boundary between two grains results symmetric, plane and oriented at the angle

$$
\varphi=\theta_{0, i} / 2-\beta \equiv \gamma-\theta_{0, i} / 2 .
$$

To obtain bicrystal with the symmetric tilt boundary it is necessary to specify the rotation axis indices, $\langle u v t w\rangle$, special misorientation angle, $\theta_{0, i}$, to determine crystallographic position of the boundary in the coincidence sites lattice (CSL) and to give a spatial orientation of this boundary, i.e. the angle $\varphi$. These bicrystal parameters must correspond to lattice parameters of the given material. At the present work for hcp-lattice of $\mathrm{Zn}$ of $99.997 \%$ purity the next parameters of the bicrystal were specified: symmetric tilt boundary, rotation axis indices, $<1120>$, special misorientation angle, $\theta_{0, i}=94^{\circ}$, spatial orientation of the boundary, $\varphi=0$. These given parameters correspond to the twin misorientation and the twin boundary, directed along the crystal axis.

In accordance with these parameters the tilt planes of all the five sections of the mold unit were made tilted at angle of $47^{\circ}$ in the seed-crystal transition area. To satisfy the condition $\varphi=0$ the seed plane (0001) was also oriented at the same angle of $47^{\circ}$. The simultaneous growth of five $\mathrm{Zn}$ bicrystals was carried out applying the oriented crystallization technique in the setup described in [8]. 


\section{Results and discussion}

Result of exploiting the hetero-homoepitaxy approach for growing of five $\mathrm{Zn}$ bicrystals illustrates the photo in Fig. 3. All bicrystals are oriented identically keeping the orientation of the common single-crystal seed. One of the bicrystals was turned by $90^{\circ}$ and indented at the wide face to visualize the longitudinal grain boundary trace and two traces corresponding to (0001) planes in each grain. The (0001) plane positions are shown schematically in Fig. 4. All the bicrystals satisfy the given parameters, i.e. they are twinned.

The obtained result gives an evidence of the successful grows of several bicrystals from one single-crystal seed involving the HHE phenomenon and keeping the specified geometric conditions. These geometric conditions are concerned with the relative spatial misorientation of the crystalline lattices of the main and HHE grains, the crystallization front and the mold plane. Positive result is possible when two geometric conditions are met simultaneously.

One of them requires that relative orientations of the crystalline lattices of the main and HHE crystals, or more precisely, their misorientation angles, should correspond to the coincidence site lattice having a high bulk density of the site coincidence, $\sum$. In this case the grain boundary plane should coincide with the CSL-plane having the high surface density of coincidence sites, $\sum_{b}$. For the $\mathrm{Zn}$ lattice the values of $\sum \leq 29$ and $\sum_{b} \leq 3$ were found experimentally.

The other requirement refers to misorientation of the crystallization front and the mold unit surface. The growth conditions become favorable when at the point of HHEgrain nucleation the crystallization vector projection onto the mold surface normal is directed towards the melt. In other words, the scalar product of the unit vectors must be positive

$$
\cos \alpha=\boldsymbol{n}_{\boldsymbol{i k}} \cdot \boldsymbol{n}_{\boldsymbol{m}}>0
$$

where $\alpha$ is angle between the normals, $\mathbf{n}_{i k}$ is normal to the crystallization front directed towards its displacement, $\mathbf{n}_{m}$ is normal to the mold surface at the nucleation point directed towards the melt. If the misorientation angle of bicrystal corresponds to the CSL with $\sum \leq 29$ and $\sum_{b} \leq 3$ the useful

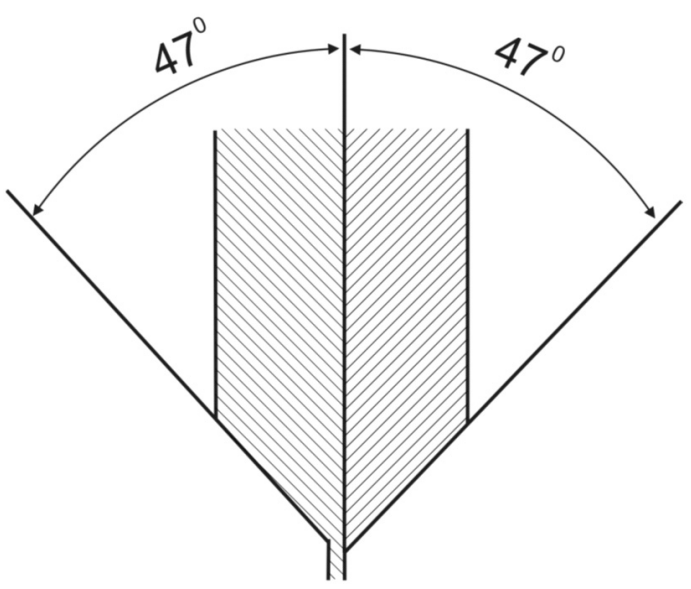

Fig. 4. Orientations of the planes (0001) for obtained twin bicrystals (shading angels).

HHE-involving growth of the bicrystals makes up almost $100 \%$. This regards to the twinned and other $\mathrm{Zn}$ bicrystals when the rotation axis has $\langle 11 \overline{2} 0\rangle$ direction as well as to $\mathrm{Cd}$ bicrystals since $\mathrm{Zn}$ and $\mathrm{Cd}$ lattice parameters and its special misorientation angles are close.

However, if the rotation axis has $<10 \mathrm{T0}>$ direction not all of the grown bicrystals may satisfy the given parameters. The fact is that in the planes $(0001)$ of the both growing grains the axis $<10 \mathrm{~T} 0>$ is perpendicular to the axis $<10 \overline{2} 0>$ which simultaneously belongs to the wide face plane of the mold. This wide face plane and (0001) planes of the main and HHE grains make angle of $90^{\circ}$, which is close to the angle of $94^{\circ}$ of the special twin misorientation. As a result, one or two parasitic twin nuclei can arise on the vertical wall of the mold and attach to the growing grains with the given parameters. At the twin orientation each growing grain may have one attached parasitic nucleus. The parasitic growth of the attached twin/twins can even suppress the growth of the specified grains. According to [9] the asymmetry of the thermal field is the contributing factor to promote this parasitic growth, if the asymmetry parameter, $k$, is

$$
k=r / 0.5 D>1,
$$

where $r$ is displacement of the curvature peak of the crystallization front from the central axis, $D$ is lateral crystal size tacked along the $r$-displacement. Growth of the parasitic nucleus is impossible in the interval $0<k<1$. Normally, the crystallization front is slightly convex. When the crystal- 
lization front is symmetric $(r=0)$, the condition $k=0$ fulfils for the bisrystal growing in the mold central section. However, for the crystals from lateral sections $k>1$ is valid. In this case a parasitic twin nucleus can grow because its crystallization vector is directed towards the melt (see Fig. 1, vector C). Therefore, the central bicrystal from the set gains the most favorable conditions due to $k=0$. The neighboring crystals experience $k>1$. Since curvature of the crystallization front is rather small, the growth direction of parasitic twin nucleus almost coincides with the main direction of crystallization. For this reason the nucleus either may not grow or may shoot in the thin near-surface layer. The island nucleation of the near-surface twins is also possible in this case.

If the thermal field is asymmetric, the value of coefficient $k$ is own for each bicrystal in the set determining conditions for parasitic nucleus growth on the vertical wall of the mold unit.

\section{Conclusions}

The simultaneous growth of five $\mathrm{Zn}$ bicrystals identically oriented by common single-crystal seed is realized for the first time exploiting the hetero-homoepitaxy phenomenon.

The growth results were found depending on the next geometric conditions: i) misorientation angle between the main and HHE grains must correspond to the coincidence site lattice having the high bulk density of site coincidence, $\sum$ and the grain boundary plane should coincide with the CSL-plane having high surface density of coincidence sites, $\sum_{b}$. For $\mathrm{Zn}$ and $\mathrm{Cd}$ these parameters were found $\sum \leq 29$ and $\sum_{b} \leq 3$; ii) at the point of HHE-grain nucleation the crystallization vector projection onto the mold surface normal must be directed towards the melt. This condition is dependent on relative positions of the crystallization front and the mold surface.

The positive grows output is determined by asymmetry coefficient, $k$, of the thermal field. When the rotation axis is $\langle 11 \overline{2} 0\rangle$, the useful grows output is almost $100 \%$ at any $k$-value including $k>1$. In the case of $<10 \mathrm{~T} 0>$ direction of rotation axis the effective bicrystal growth is only possible at $0<$ $k<1$.

Acknowledgments. The author is grateful to Dr. N.Isaev for helpful discussions.

\section{References}

1. A.I.Orlov, A.N.Perevezentsev, V.V.Rubin, Grain Boundaries in Metals, in: Dostizhenia Otechestvennogo Metallovedenia, Metallurgia, Moscow (1980) [in Russian].

2. H.Gleiter, B.Chalmers. High-angle Grain Boundaries, Moskow, Mir,376 (1975).

3. V.M.Kosevich, V.M.Ievlev, L.S.Palatnik et al., Structure of Intercrystalline and Interphase Boundaries, Metallurgia, Moscow (1980) [in Russian].

4. R.L.Fleischer, R.S.Davis, Trans.Met.Soc. AJME, 125, 665 (1959).

5. Yu.G.Kazarov, F.F.Lavrentiev, Functional Materials, 4, 409 (1997).

6. Yu.G.Kazarov, F.F.Lavrentiev, Functional Materials, 3, 334 (1996).

7. Yu.G.Kazarov, F.F.Lavrentiev, Cryst. Res. and Technol., 18, 107 (1983).

8. Yu.G.Kazarov, F.F.Lavrentiev, Pribory $i$ Tekhnika Eksperimenta, No.5, 222 (1983).

9. Yu.G.Kazarov, F.F.Lavrentiev, Met.Phys. Adv. Tech., 15, 852 (1996). 